\title{
Sciendo
}

\section{Those Who Shall Be Identified: The Data Protection Aspects of the Legal Framework for Electronic Identification in the European Union}

\section{Jozef Andraško Matúš Mesarčík}

Faculty of Law Comenius University in Bratislava Šafárikovo nám. č. 6 Bratislava 810 00, Slovakia Email: jozef.andrasko@flaw.uniba.sk Email: matus.mesarcik@flaw.uniba.sk

\begin{abstract}
The article focuses on the intersections of the regulation of electronic identification as provided in the eIDAS Regulation and data protection rules in the European Union. The first part of the article is devoted to the explanation of the basic notions and framework related to the electronic identity in the European Unionthe eIDAS Regulation. The second part of the article discusses specific intersections of the eIDAS Regulation with the General Data Protection Regulation (GDPR), specifically scope, the general data protection clause and mainly personal data processing in the context of mutual recognition of electronic identification means. The article aims to discuss the overlapping issues of the regulation of the GDPR and the eIDAS Regulation and provides a further guide for interpretation and implementation of the outcomes in practice.
\end{abstract}

Keywords: eIDAS Regulation, electronic identification, electronic identification means, data protection, GDPR, mutual recognition 


\section{Introduction}

Until 2012, the legal system of the European Union (EU) did not contain a comprehensive binding legislative act on mutual recognition of electronic identification means in the context of public online services. However, several non-binding documents and projects related to the implementation of eGovernment services may be perceived as predecessors of the discussed regulation. The projects FIDIS, STORK, and STORK 2.0 have to be mentioned at least. Project FIDIS (Future of Identity in the Information Society) focused on the issues of identification and authentication from the technical point of view but several regulation recommendations are provided in the outcomes as well. The project lasted from 2004 until 2009 and 24 multidisciplinary institutions took part in it (Project FIDIS, n.d.). Project STORK (Secure idenTity acrOss boRders linKed) was conducted between 2008 and 2011 and analysed potential issues related to the identification and authentication in cross-border eGovernment services. The sequel of the project STORK, titled 2.0 , follows the outcomes of the first project and implemented four pilot versions of applications for cross-border identification and authentications in different areas of life (banking, academia, public services, and infrastructure). This project was largely focused on the authentication of legal persons, liability, and data protection area (Project STORK, n.d.).

As a result of the regulatory vacuum and legislative proposals, the legislator decided to repeal the obsolete Directive 1999/93/EC of the European Parliament and of the Council of 13 December 1999 on a Community framework for electronic signatures and merge the regulation of electronic signatures with recognition of electronic identification means and provisions related to trust services. The final wording of the new regulation was adopted on 23 July 2014 and entered into force on 17 September 2014, being applicable from 1 July 2016 with the exception of certain provisions listed in Article 52. The regulation is supplemented by several implementing regulations issued by the European Commission (European Commission, n.d., b).

The adopted Regulation (EU) no. 910/2014 of the European Parliament and of the Council of 23 July 2014 on electronic identification and trust services for electronic transactions in the internal market and repealing Directive 1999/93/EC (hereinafter referred to as the eIDAS Regulation) is part of the development of a Digital Single Market within the internal market of the EU. This is enshrined in the introductory recitals of the eIDAS Regulation as the aim of the legal instrument is to promote and enhance trust in 
electronic transactions (eIDAS Regulation, Recital 2). The importance of the regulation of electronic identification as part of the Digital Single Market is strengthened by the explicit acknowledgment of the law contributing to overcoming the digital challenges of the internal market (eIDAS Regulation, Recital 6). However, the adoption of the eIDAS Regulation shall be put into the context of a complex strategy of the EU to tackle the creation and legal issues of the Digital Single Market (eIDAS Regulation, Recital 6).

Following Article 16 of the Treaty on Functioning of the European Union and introducing the separate right for data protection in the EU Charter of Fundamental Rights in Article 8, regulation of the processing of personal data has become the crucial point within the Digital Single Market. Protection of the identity (physical or virtual) is a cornerstone of the Article 8 of the EU Charter stemming from previous international documents regulating the protection of data (Fuster, 2014). The right to personal data protection includes the protection of identity as the essence of the right in question (Porcedda, 2018, p. 16; Tzanou, 2013, pp. 88-89; Romano, 2013; Razmetaeva, 2020, pp. 60-62).

With this aspect in mind, EU legislator replaced the outdated Directive 95/46/ $\mathrm{EC}$ on the protection of personal data with new technology adaptable framework represented by several legal acts, most notably Regulation (EU) 2016/679 of the European Parliament and of the Council of 27 April 2016 on the protection of natural persons with regard to the processing of personal data and on the free movement of such data, and repealing Directive 95/46/EC (General Data Protection Regulation, hereinafter referred to as GDPR). The GDPR applies to both private and public sector actors (GDPR, Art. 1(1)) including the provision of public online services (see Andraško, 2017). Therefore the purpose of the article is to provide a critical analysis of the intersections between the eIDAS Regulation and the GDPR. The importance of the issue shall be highlighted in the context of the ongoing COVID-19 pandemic and the emergence of the use of digital services (Hamulák \& Nevická, 2020).

This introduction is followed by a brief analysis of the structure of the eIDAS Regulation particularly focusing on the concept of the mutual recognition of the electronic identification means and basic concepts regulated by the legislation. The next part consists of the analysis of the data protection aspects of the eIDAS Regulation in the context of human rights perspectives, the applicability of the framework, basic definitions, and directly related aspects of the GDPR. Conclusions are provided in the final part of the contribution. 


\section{2. eIDAS Regulation}

The adoption of Regulation (EU) no. 910/2014 of the European Parliament and of the Council of 23 July 2014 on electronic identification and trust services for electronic transactions in the internal market and repealing Directive 1999/93/EC (eIDAS Regulation) represents the first complex legislation concerning identification and authentication of persons in cyberspace in the EU (see Andraško, 2016, pp. 75-78).

The main aim of the eIDAS Regulation is to build trust in the online environment.

The trust in the online environment is key to economic and social development. Lack of trust, in particular, because of a perceived lack of legal certainty, makes consumers, businesses, and public authorities hesitate to carry out transactions electronically and to adopt new services. (eIDAS Regulation, Recital 1)

In that regard, the eIDAS Regulation provides a "common foundation for secure electronic interaction between citizens, businesses, and public authorities, thereby increasing the effectiveness of public and private online services, electronic business, and electronic commerce in the EU." The aforementioned actions should lead to enhancing trust in electronic transactions in the internal market. (eIDAS Regulation, Recital 2)

Furthermore, the eIDAS Regulation aims to "remove existing barriers to the cross-border use of electronic identification means used in the Member States to authenticate, for at least public services" (eIDAS Regulation, Recital 12). In that regard, it has to be recalled that the eIDAS Regulation does not aim to intervene concerning electronic identity management systems and related infrastructures established in the Member States.

The eIDAS Regulation is directly binding and enforceable in all Member States of the EU (hereinafter referred to as the Member State). However, it should be noted that the eIDAS Regulation applies to the extent of trust services (electronic signature, electronic seal, electronic time stamp, etc.) from 1 July 2016, and provisions regulating the concept of the mutual recognition of electronic identification means came into effect on 29 September 2018 (eIDAS Regulation, Art. 52 (1) (c)).

The eIDAS Regulation is not a sector-specific legislation and rather provides a common foundation for secure electronic interaction between citizens, businesses, and public authorities. 
The provisions of the eIDAS Regulations should increase the effectiveness of public and private online services, electronic business, and electronic commerce in the EU. In that regard, it deals with all aspects of the internal market, irrespective of whether the actors are consumers, businesses, or public authorities.

\subsection{The subject matter of the eIDAS Regulation}

Provisions of the eIDAS Regulation should enhance trust in electronic transactions in the internal market by "providing a common foundation for secure electronic interaction between citizens, businesses and public authorities, thereby increasing the effectiveness of public and private online services, electronic business and electronic commerce in the Union." (eIDAS Regulation, Recital 2) To achieve such a goal, the eIDAS Regulation:

a) Lays down the conditions under which the Member States recognise electronic identification means of natural and legal persons falling under a notified electronic identification scheme of another Member State;

b) Lays down rules for trust services, in particular for electronic transactions;

c) Establishes a legal framework for electronic signatures, electronic seals, electronic time stamps, electronic documents, electronic registered delivery services, and certificate services for website authentication. (eIDAS Regulation, Art. 1(a-c))

For the purposes of this article, we will focus on concepts related to the mutual recognition of electronic identification means.

\subsection{The basic concepts in the context of mutual recognition}

Mutual recognition of electronic identification means can by clarified by specific concepts-in particular, electronic identification scheme, electronic identification means, electronic identification, personal identification data, authentication, and assurance levels.

An electronic identification scheme is defined as a "system for electronic identification under which electronic identification means are issued to natural or legal persons, or natural persons representing legal persons" (eIDAS Regulation, Art. 3(4)). 
The electronic identification scheme includes two types of services, in particular:

a) issuance of electronic identification means, and

b) securing the authentication process.

The electronic identification scheme has to meet conditions according to Article 7 of the eIDAS Regulation to be considered eligible for notification. When the electronic identification scheme is eligible for notification, the Member State will provide, at least 6 months before, the description of the electronic identification scheme to the other Member States and the European Commission (eIDAS Regulation, Art. 7(g)). This phase is called pre-notification.

After the pre-notification phase, a peer review of electronic identification schemes follows. The peer-review process is regulated by the Commission implementing Decision (EU) 2015/296 of 24 February 2015 establishing procedural arrangements for cooperation between Member States on electronic identification pursuant to Article 12 (7) of the eIDAS Regulation (hereinafter referred to as the Implementing decision 2015/296). ${ }^{1}$ Peer review is a "mechanism for cooperation between Member States designed to ensure interoperability and security of notified electronic identification schemes" (Implementing decision 2015/296, Art. 7(1)). As a result of the peerreview process, an official opinion is issued by the Cooperation Network. The official opinion provides indications of whether electronic identification is in compliance with the requirements of eIDAS Regulation or not. In the case of a positive official opinion, the notifying Member State can issue a formal notification to the European Commission.

The Commission will publish a notification in the Official Journal of the European Union within two months from the date of receipt of that notification (eIDAS Regulation, Art. 7(3)).

Mutual recognition shall take place no later than 12 months after the Commission publication (eIDAS Regulation, Art. 6(1)).

Member States should not be obliged to notify their electronic identification schemes to the Commission. The choice to notify the Commission of all, some or none of the electronic identification schemes used at national

1 Commission implementing decision (EU) 2015/296 of 24 February 2015 establishing procedural arrangements for cooperation between Member States on electronic identification pursuant to Article 12(7) of Regulation (EU) no. 910/2014 of the European Parliament and of the Council on electronic identification and trust services for electronic transactions in the internal market. 
Those Who Shall Be Identified: The Data Protection Aspects of the Legal Framework for Electronic Identification in the European Union

level to access at least public online services or specific services is up to Member States. (eIDAS Regulation, Recital 13)

Pursuant to Article 3(2) of the eIDAS Regulation, electronic identification means is defined as "material and/or immaterial unit containing person identification data and which is used for authentication for an online service". The electronic identification means aims at the authentication of a person to use the online service in another Member State. In light of that purpose, the eIDAS Regulation does not define the specific types of electronic identification means but rather the principle of technological neutrality is applied. For example, the material units containing person identification data are a USB token or an electronic chip that is included in the identity card. On the other hand, an electronic certificate is an example of an immaterial unit.

According to Article 7 (a) of the eIDAS Regulation, the electronic identification means under the electronic identification scheme can be issued "(i) by the notifying Member State; (ii) under a mandate from the notifying Member State; (iii) independently of the notifying Member State and are recognized by that Member State".

According to Recital 13 of the eIDAS Regulation, Member States should remain "free to use or to introduce means for electronic identification for accessing online services". Moreover, they should also be able to decide whether to "involve the private sector in the provision of those means" (eIDAS Regulation, Recital 13). The private sector should be encouraged by the Member States to "voluntarily use electronic identification means under a notified scheme for identification purposes when needed for online services or electronic transactions" (eIDAS Regulation, Recital 17). The possibility to use such electronic identification means would make it easier for businesses and citizens to access their online services across borders (eIDAS Regulation, Recital 17).

According to Article 3(1) of the eIDAS Regulation, electronic identification is defined as "the process of using person identification data in electronic form uniquely representing either a natural or legal person, or a natural person representing a legal person". In this regard, three types of entities can be identified under the eIDAS Regulation, in particular:

a) natural persons,

b) legal persons, and

c) natural persons representing a legal person. 
Person identification data means a "set of data enabling the identity of a natural or legal person, or a natural person representing a legal person to be established" (eIDAS Regulation, Art. 3). The Implementing regulation 2015/1501 defines a minimum set of person identification data uniquely representing a natural or a legal person. The minimum data set for a natural person shall contain all of the following mandatory attributes (Annex of the Implementing regulation 2015/1501):

a) current family name(s),

b) current first name(s),

c) date of birth,

d) a unique identifier constructed by the sending Member State in accordance with the technical specifications for cross-border identification and which is as persistent as possible in time.

Furthermore, the minimum data set must contain one or more of the following additional attributes (Annex of the Implementing regulation 2015/1501):

a) first name(s) and family name(s) at birth,

b) place of birth,

c) current address,

d) gender.

A person's identification data uniquely representing the person in question is attributed to a natural or legal person, or a natural person representing a legal person at the time the electronic identification means under which that scheme is issued (eIDAS Regulation, Art. 7(d)). Identification data have to be in compliance with technical specifications, standards and procedures for the relevant assurance level set out in the Commission Implementing Regulation (EU) 2015/1502 of 8 September 2015 on setting out minimum technical specifications and procedures for assurance levels for electronic identification means pursuant to Article 8(3) of the eIDAS Regulation.

Furthermore, the "notifying Member State ensures the availability of authentication online, so that any relying party established in the territory of another Member State can confirm the person identification data received in electronic form" (eIDAS Regulation, Art. 7(f)).

Besides, the "cross-border authentication shall be provided free of charge when it is carried out in relation to a service online provided by a public sector body" (eIDAS Regulation, Art. 7(f)). 
Furthermore, Member States

shall not impose any specific disproportionate technical requirements on relying parties intending to carry out such authentication, where such requirements prevent or significantly impede the interoperability of the notified electronic identification schemes (eIDAS Regulation, Art. 7(f)).

Regarding the use of personal identification data during the process of authentication. processing shall include only " those identification data that are adequate, relevant, and not excessive to grant access to that service online" (eIDAS Regulation, Recital 11).

\section{Assurance levels characterize}

the degree of confidence in electronic identification means in establishing the identity of a person, thus assuring that the person claiming a particular identity is the person to which that identity was assigned. The assurance level depends on the degree of confidence that electronic identification means provides in claimed or asserted identity of a person taking into account processes (e.g., identity proofing and verification, and authentication), management activities (e.g., the entity issuing electronic identification means and the procedure to issue such means) and technical controls implemented. (eIDAS Regulation, Recital 16)

Under the eIDAS Regulation, three types of assurance levels are defined, in particular, assurance level low, substantial and high.

\begin{tabular}{|l|l|}
\hline eIDAS assurance levels & $\begin{array}{l}\text { Example of electronic identification } \\
\text { means }\end{array}$ \\
\hline Assurance level low & $\begin{array}{l}\text { Login name and password that was sent } \\
\text { remotely. }\end{array}$ \\
\hline $\begin{array}{l}\text { Assurance level } \\
\text { substantial }\end{array}$ & $\begin{array}{l}\text { Login name and password and one-time } \\
\text { password (two-factor authentication); the } \\
\text { physical presence of the applicant is not } \\
\text { required during registration (application for the } \\
\text { issue of an electronic identification means and } \\
\text { its delivery). }\end{array}$ \\
\hline Assurance level high & $\begin{array}{l}\text { Identity card with electronic chip and PIN } \\
\text { code. }\end{array}$ \\
\hline
\end{tabular}

The concept of assurance levels is crucial in the process of mutual recognition of electronic identification means and is associated with three condition for the mutual recognition of electronic identification means. 
The notification of the electronic identification scheme is the first condition for the mutual recognition of electronic identification means.

The second condition for the mutual recognition of electronic identification means by another Member State is to ensure the

assurance level of the electronic identification means corresponding to an assurance level equal to or higher than the assurance level required by the relevant public sector body to access that service online in the first Member State, provided that the assurance level of that electronic identification means corresponds to the assurance level substantial or high. (eIDAS Regulation, Art. 6(1)(b)).

The fulfillment of the condition can be demonstrated in the following example. The public sector body from one Member State requires a substantial or high assurance level to access its online service. If the citizen of another Member State has the electronic identification means at the same or higher assurance level as required by the public sector body of the first Member State, the condition is fulfilled.

The third condition for the mutual recognition of electronic identification means is that "the relevant public sector body uses the assurance level substantial or high in relation to accessing that service online" (eIDAS Regulation, Art. 6(1)(b-c)).

An electronic identification means which is issued under the electronic identification scheme included in the list published by the European Commission under Article 9 of the eIDAS Regulation and which corresponds to the assurance level low may be recognized by public sector bodies for cross-border authentication for the service provided online by those bodies. (eIDAS Regulation, Art. 6(2))

In other words, it is up to the Member States whether they recognize the electronic identification means which corresponds to the assurance level low.

It is necessary to point out that the application of the mutual recognition principle does not automatically mean that Member States are obliged to grant access to online services.

The principle of mutual recognition should only relate to authentication for an online service. The access to those online services and their final delivery to the applicant should be closely linked to the right to receive such services under the conditions set out in national legislation. (eIDAS Regulation, Recital 14) ${ }^{2}$

2 E.g., the requirement for the provision of public administration electronic service related to welfare services can be citizenship or permanent residence. 


\section{GDPR meets eIDAS: Data protection aspects of the eIDAS Regulation}

On 4 June, the European Commission introduced the proposal for the new eIDAS regulation. As the proposed act raised several data protection issues, the European Data Protection Supervisor (EDPS) had been consulted with before the publication. The findings of the EDPS are available in its opinion from the 27 September 2012 (EDPS, 2012). Due to the ongoing legislative procedure on new data protection framework, the EDPS opinion is drafted in a general manner focusing on the specifics of Directive 95/46/EC and mentioning the GDPR only briefly in one footnote (EDPS, 2012). However, many aspects mentioned in the EDPS opinion are still applicable to the current EU general data protection legal framework represented by the GDPR, which became applicable on 25 May 2018.

The GDPR aims to provide a framework for free flow of personal data in the EU (GDPR, Art. 1(3)) together with stipulating the basic rules for the processing of personal data (GDPR, Art. 1(1)) while respecting the fundamental rights and freedoms of natural persons (GDPR, Art. 1(2)). Taking into account the broad definition of processing (GDPR, Art. 4(2)) and personal data (GDPR, Art. 4(1)) in connection with Recital 26; see also Article 29 Data Protection Working Party, 2007), it shall be concluded that the GDPR applies to organizations under the requirements of eIDAS Regulation (for further concepts in the context of new technologies see Kesa \& Kerikmäe, 2020). This is mainly because person identification data necessary for the provision of electronic public services and trust services in most of the cases qualify as personal data in the sense of the GDPR. Furthermore, providing the aforementioned services is usually carried out by organizations located in the EU (e.g., public bodies providing electronic public services and trust services providers) or providing services to the data subjects in the EU (trust services provides located outside of the EU) (European Commission, n.d., d). Although the eIDAS Regulation is not explicitly recognized in the text of the GDPR, references to the EU data protection framework (Directive 95/46/EC) are presented in the recitals and normative text of the eIDAS Regulation. Recital 11 of the eIDAS Regulation states a need for "full compliance with the principles relating to the protection of personal data in the EU data protection framework" (eIDAS Regulation, Recital 11). These intersections are analysed in the following parts. 


\subsection{Person identification data and personal data}

The discussed legislation oscillates around the notion of electronic identification, which means the process of using person identification data electronically which allows the unique identification of natural or legal persons (eIDAS Regulation, Art. 4(1)). The definition of identity is absent in the normative text of the eIDAS Regulation. However, the interpretation shall include only objective identity that comprises of "objective detectable identifying elements of an individual" (Zaccaria et al., 2020, p. 52). On the other hand, subjective identity is not a matter of regulation in the discussed legislation. Subjective identity may be described as a "social display of personal identity" (Zaccaria et al., 2020, p. 52). Identity consists of person identification data defined in Article 3(3) of the eIDAS Regulation. Comparing the definitions of person identification data in the eIDAS Regulation and personal data in the GDPR, it should be noted that the definition of person identification data is narrower and wider than the definition of personal data at the same time. Personal data is defined as "any information relating to an identified or identifiable natural person" (GDPR, Art. 4(1)). The GDPR further stipulates the concept of an identifiable natural person who can be

identified, directly or indirectly, in particular by reference to an identifier and demonstrative list of identifiers comprised of a name, an identification number, location data, an online identifier, or to one or more factors specific to the physical, physiological, genetic, mental, economic, cultural or social identity of that natural person. (GDPR, Art. 4(1))

On the one hand, the definition of person identification data does not apply in the context of subjective information that may still be qualified as personal data in the sense of the GDPR (see also Article 29 Data Protection Working Party, 2007). The purpose of the process of identification is the verification of the identity of the user, therefore naturally emphasizing objective identifiers. On the other hand, one may say that the definition of person identification data is wider as it applies to legal persons as well. The application of the EU data protection framework to legal persons is limited (Sloot, 2015) and the human rights aspects of the right to data protection are repeatedly highlighted in the legislation (GDPR, Recitals 1-2). 
Those Who Shall Be Identified: The Data Protection Aspects of the Legal Framework for Electronic Identification in the European Union

\subsection{General data protection clause (Article 5)}

The general clause establishing the requirement of compliance with data protection rules is provisioned in Article 5 of the eIDAS Regulation. Article 5 (1) sets out that "the processing of personal data shall comply with Directive 95/46/EC" (eIDAS Regulation, Art. 5(1)). In terms of the principle of mutual recognition of electronic identification means in the context of providing online services processing personal data for the authentication shall meet three criteria. The necessary identification data "shall be adequate, relevant, and not excessive to grant access to that service online" (eIDAS Regulation, Recital 11). These principles are explicitly part of the basic principles of data protection in Article 5 of the GDPR. Requirements of adequacy and relevancy are reflected in the principle of data minimization in Article 5(1) (c) of the GDPR. The principle of data minimization states that "personal data shall be adequate, relevant and limited to what is necessary in relation to the purposes for which they are processed" (GDPR, Art. 5 (1)(c)). The aim of the necessity obligation should be understood as applicable to the quality and quantity of persona data (GDPR, Recital 39).

The requirement of non-excessiveness may be found in the wording of the principle of purpose limitation: "Personal data shall be collected for specified, explicit and legitimate purposes and not further processed in a manner that is incompatible with those purposes" (GDPR, Art. 5(1) (b)). The principle of purpose limitation is closely connected to the general principle of proportionality (Court of Justice of the European Union, 2009). However, the analysed requirement is also part of the principle of data minimization discussed above.

Secondly, providers of trust services and supervisory bodies shall follow the requirements of confidentiality and security stemming from the EU data protection law. Both features stem from the principle of integrity and confidentiality in the GDPR stating that

personal data shall be processed in a manner that ensures appropriate security of the personal data, including protection against unauthorized or unlawful processing and against accidental loss, destruction or damage, using appropriate technical or organizational measures (GDPR, Art. 5(1)(e)).

The aspect of security is enshrined in Articles 32 of the GDPR (general clause) and Article 33 and 34 (notification of personal data breaches obligations). The general security clause states that 
the controller and the processor shall implement appropriate technical and organizational measures to ensure a level of security appropriate to the risk taking into account the state of the art, the costs of implementation and the nature, scope, context and purposes of processing as well as the risk of varying likelihood and severity for the rights and freedoms of natural persons (GDPR, Art. 32(1)).

Demonstrative enumeration of security measures is provided in the same Article (see GDPR, Art. 32). Further normative clarifications are related to the obligation of comprehensive risk analysis (GDPR, Art. 32(2)), possibility of compliance with the security requirements prescribed by the GDPR by adherence to the approved code of conduct or certification mechanisms (GDPR, Art. 32(3)) and external and internal agreements setting limits of instructions with persons acting under the authority of a controller or a processor (GDPR, Art. 32(4)). In terms of confidentiality, the GDPR contains an opening clause in Article 90 allowing Member States to set forth specific rules to balance the powers of supervisory authorities towards national obligations of secrecy (confidentiality) of specific controllers, e.g., attorneys, tax advisors, or doctors (GDPR, Art. 90).

The eIDAS Regulation further provides that "the use of pseudonyms in electronic transactions is not prohibited by the regulation" without prejudice towards pertinent data under the national legislation (eIDAS Regulation, Art. 5(2)). The provision is further accompanied by Recital 33 of the eIDAS Regulation clarifying that "provisions on the use of pseudonyms in certificates should not prevent Member States from requiring identification of persons pursuant to Union or national law" (eIDAS Regulation, Recital 33). The norm in question shall be read in the light that Member States shall not prohibit the use of pseudonyms within electronic transactions as pseudonyms offer a certain level of protection from the point of data protection rules. The EDPS adds that pseudonyms are still considered personal data (EDPS, 2012, p. 5). Although pseudonyms are not explicitly defined in the eIDAS Regulation, the notion of pseudonymization is covered by the GDPR. Therefore, pseudonymization refers to

the processing of personal data in such a manner that the personal data can no longer be attributed to a specific data subject without the use of additional information, provided that such additional information is kept separately and is subject to technical and organizational measures to ensure that the personal data are not attributed to an identified or identifiable natural person (GDPR, Art. 4(5)). 
Those Who Shall Be Identified: The Data Protection Aspects of the Legal Framework for Electronic Identification in the European Union

The wording of Article 5(2) does not encourage using pseudonyms in the process of electronic transactions, and merely acknowledges the possibility of using the technique in compliance with the GDPR (GDPR, Recital 29).

\subsection{Cooperation and interoperability of the eID schemes}

The description of the process of mutual recognition of identification means is presented in Section 2.2 of this article. Due to Article 12 (1) of the eIDAS Regulation, the national identification schemes that are duly notified shall be interoperable therefore creating an interoperability framework (eventually among all) EU Member States (Cupiers \& Schroers, 2014). Specific criteria of the interoperability framework are provisioned in Article 12(3) of the eIDAS Regulation: (i) technological neutrality; (ii) compliance with European international standards; (iii) implementation of principles of Privacy by Design; and (iv) ensuring the protection of personal data following EU data protection rules (eIDAS Regulation, Art. 12(3)).

Specifically, the eIDAS Regulation obliges the interoperability framework consisting of the eID schemes to follow the principles of Privacy by Design (PbD) (eIDAS Regulation, Art. 12(3) (c)). It is of the essence to note that the requirement in questions does not refer to "data protection by design and by default" as enshrined in Article 25 of the GDPR but instead focuses on the broader concept of the $\mathrm{PbD}$. This is mainly due to the fact that at the time of drafting of the eIDAS Regulation, the concept of data protection by design and by default was fairly unknown to EU data protection laws. As Bygrave notes, the "thrust of the respective ideas" is similar (Bygrave, 2017, p. 106). The main focus of the $\mathrm{PbD}$ is to implement privacy protection in the respective design of the electronic systems or applications from the design (development) phase to strengthen preventive reactions towards potential threats or violations of privacy. Rubinstein alternatively defines $\mathrm{PbD}$ as "the adoption of processes, systems, procedures, and policies_-any of which may also have a technological dimension - and which may be referred to collectively as privacy safeguards" (Rubinstein, 2011, pp. 1421-1422). Deriving from the obligation of facilitating the principle of $\mathrm{PbD}$ for the Interpretability framework, it is of the opinion of the authors that eID schemes shall be in compliance with Article 13(2)(c) designed in a privacy-compliant manner following the principles of $\mathrm{PbD}$ as well (Tsakalakis et al., 2016, p. 168). It is worth noting that the provision in question explicitly refers to the principles of $\mathrm{PbD}$. These are further analysed and elaborated in the text drafted by Dr. Ann Cavoukian, former Information and Privacy Commissioner Ontario, Canada (Cavoukian, 2011). 
What shall be the attributes of eID schemes taking into account the principles of $\mathrm{PbD}$ by Cavoukian? Firstly, the principle of proactiveness and preventiveness requires providers of eID schemes to anticipate privacy issues and not rely on analyzing privacy breaches after they occur. "Privacy by Design comes before-the-fact, not after" (Cavoukian, 2011). Secondly, privacy protection shall be constructed as a default setting, which means that the protection of privacy shall be set up on the maximum level possible in the case that the user does not alter privacy settings. Privacy as a default setting shall be built within eID schemes. Thirdly, as already emphasized, privacy shall be embedded in the design of the eID scheme. This practically means that privacy is an integral part of the scheme and not a necessary add-on. Fourthly, there shall be full functionality of privacy within eID schemes and not requiring any kind of trade-off, e.g., between privacy and security. Fifthly, the eiD schemes shall be obliged to follow end-to-end-security thus protecting privacy and flow of identification data during the whole life-cycle of data processing. Sixthly, principles of $\mathrm{PbD}$ entail visibility and transparency. Therefore, users of eID schemes shall have the option to verify the promised protection of privacy. Lastly, respect for user privacy shall be implemented above all. eID schemes shall be designed as user-centric "offering such measures as strong privacy defaults, appropriate notice, and empowering user-friendly options" (Cavoukian, 2011). Further recommendations concerning the implementation of $\mathrm{PbD}$ in the authentication services are provided by The European Union Agency for Cybersecurity (ENISA) in the report named Privacy and Data Protection by Design: From Policy to Engineering (ENISA, 2014).

It remains unclear whether compliance with the principles of $\mathrm{PbD}$ would suffice for the obligations prescribed by Article 25 of the GDPR. European Data Protection Board in its Guidelines on Article 25 Data Protection by Design and by Default (EDPB, 2019) does not answer the question of the relationship between PbD and Article 25. Bygrave (2017) concludes that the answer to the question may be twofold. On the one hand, obligations stemming from Article 25 of the GDPR may be similarly perceived as principles of $\mathrm{PbD}$ by Cavoukian. On the other hand, Article 25 of the GDPR may require further and stricter implementation of organizational or technical measures not within the scope of $\mathrm{PbD}$ (Bygrave, 2017; see also Jasmontaite et al., 2018) and go beyond the requirements posed by GDPR as the personal scope of the obligation in the eIDAS Regulation is not limited to controllers of personal data (Tsakalakis et al., 2018, p. 260). Doctrine perceives Article 12(3)(c) as the anticipation of (at that time) forthcoming GDPR (Tsakalakis et al., 2018, p. 259). 
Additionally, Article 12(3)(d) requires compliance with data protection rules in terms of interoperability framework in general (eIDAS Regulation, Art. 12(3)(c)). It shall be emphasized that the eIDAS Regulation specifically highlights the principle of data minimization in terms of authentication in the context of electronic public services. In practice, the requirement means that providers of electronic public services shall require only the necessary amount of identification data for using online services from users. EDPS in its opinion recommended using privacy enhancing technologies (PETs) in the process of implementing electronic identification schemes (EDPS, 2012 , p. 5). Further proposals of the EDPS included the implementation of crucial aspects for harmonization of the schemes such as "the data fields that will be used for identification of individuals, the security requirements and the data protection safeguards" (EDPS, 2012, p. 8). The aforementioned requirements are not reflected in the wording of the eIDAS Regulation except the institution of Privacy by Design.

\section{Conclusions}

With the advent of the internet and the provision of public services at a distance, public administration had to ensure trustworthy and secure communication between entities, entrepreneurs and public administration authorities. As a result, it was necessary to create new models of identity management by implementation of new rules, procedures, and technical components dealing with electronic identity. The introduction of electronic identity management created new opportunities for the public administration, in particular collecting and processing information on the electronic identity of individuals. Consequently, electronic identity management should ensure the efficiency of the provision of electronic public administration services, increasing information security and privacy, improving the conditions for citizens to access public services, as well as increasing the provision of electronic public administration services by improving trust in online interaction with citizens.

The eIDAS Regulation as a primary legislation concerning identification and authentication of persons in cyberspace of the EU is providing a common foundation for secure electronic interaction between citizens, businesses, and public authorities. The concepts created by the eIDAS Regulation, in particular electronic identification scheme, electronic identification means, 
electronic identification, authentication and assurance levels, should increase the effectiveness of public and private online services, electronic business, and electronic commerce in the EU.

Several intersections with data protection rules represented by the GDPR are discussed in the article. Firstly, the general data protection clause in Article 5 of the eIDAS Regulation requires full compliance with data protection laws. The regulation specifically highlights the principle of data minimization and obligations of security and confidentiality. In terms of mutual recognition of electronic identification means, the principles of Privacy by Design are emphasized by the legislator for the interoperability framework of eID schemes. Fulfilling the requirements of Article 25 of the GDPR may not achieve the full compliance with an aim of facilitating the principle of $\mathrm{PbD}$ in the interoperability framework. Furthermore, each of the assurance levels prescribed by Article 8 of the eIDAS Regulation requires partially overlapping requirements with the GDPR - namely, adopting privacy policies, internal policies, training staff, due diligence with potential processors, security obligations, or processing of specific categories of persona data. The regulation of trust service providers is also connected to the processing of personal data and triggering the application of the GDPR concerning security incidents, supervisions, and compliance with data protection laws in general as a criterion for the status of qualified service providers.

The article shows a significant overlap between the eIDAS Regulation and the GDPR. Providers of online services or trust service providers caught by the scope of the eIDAS Regulation shall often keep an eye on the requirements of the GDPR as the processing of personal (identification) data is inextricably connected to these services.

\section{Acknowledgement}

This article was drafted with the support from a grant awarded by the Slovak Research and Development Agency no. APVV-17-0403 Effects of Mutual Recognition of Electronic Identification Means on Electronic Services of Public Administration and is included in a research task. 
Jozef Andraško is head of the Institute of Information Technology Law and Intellectual Property Law, Faculty of Law, Comenius University in Bratislava. He has completed study stays at the University of Iceland with a focus on international law and at Tilburg University with a focus on information and communication technology law and intellectual property law. He specializes in cybersecurity, electronic identity, open data and autonomous vehicles. As part of his legislative expertise, he was a co-author of executive regulation on the method of categorization and content of security measures of information technologies of public administration (Regulation no. 179/2020 Coll.). As a member of the Jean Monnet Network "European Union and the Challenges of Modern Society" he analyses EU cybersecurity legislation and legal issues regarding autonomous vehicles.

Matúš Mesarčík is an assistant professor at the Institute of Information Technology Law and Intellectual Property Law, Faculty of Law, Comenius University in Bratislava, where he lectures courses on personal data protection and information technology law. He regularly publishes in domestic and foreign scientific periodicals and participates in domestic and foreign conferences. He is an external lecturer at the Judicial Academy in Pezinok, Slovakia. He provides ad hoc consulting services in the field of personal data protection primarily for public authorities and is a member and expert on privacy in the civic association European Information Society Institute (EISi).

\section{Bibliography}

Andraško, J. (2016), 'Electronic identification and authentication in the context of electronic public administration services,' CER Comparative European Research, no. 2, pp. 75-78.

Andraško, J. (2017), 'Mutual recognition of electronic identification means under the EIDAS Regulation and its application issues,' AD ALTA: Journal of Interdisciplinary Research, vol. 7, no. 2, pp. 9-13.

Article 29 Data Protection Working Party (2007), Opinion 4/2007 on the concept of personal data adopted on 20th June, 01248/07/EN WP 136.

Bygrave, L. (2017), 'Data protection by design and by default: Deciphering the EU's legislative requirements,' Oslo Law Review, vol. 4, no. 2, pp. 105-120. http://doi.org/10.18261/ISSN.2387-3299-2017-02-03

Carpenter, C. (2020), 'Privacy and proportionality: Examining mass electronic surveillance under Article 8 and the Fourth Amendment,' International 
Comparative Law Review, vol. 20, no. 1, pp. 27-57.

https://doi.org/10.2478/iclr-2020-0002

Cavoukian, A. (2011), 7 Principles of Privacy by Design. Retrieved from https:// www.ipc.on.ca/wp-content/uploads/resources/7foundationalprinciples.pdf [accessed 7 Nov 2020]

Court of Justice of the European Union (2009), Judgment of the Court (Grand Chamber) of 9 November 2010, Volker und Markus Schecke GbR (C-92/09) and Hartmut Eifert (C-93/09) $v$ Land Hessen. Retrieved from https://eur-lex.europa. eu/legal-content/EN/TXT/?uri=CELEX\%3A62009CJ0092 [accessed 7 Nov 2020] CEF Digital (n.d.), 'How Does It Work? EIDAS Regulation.' Retrieved from https:// ec.europa.eu/cefdigital/wiki/pages/viewpage.action?pageId=82773030 [accessed 7 Nov 2020]

Cuijpers, C. \& Schroers, J. (2014), eIDAS as guideline for the development of a pan European eID framework in FutureID. Retrieved from https://core.ac.uk/ download/pdf/34614563.pdf [accessed 7 Nov 2020]

Directive 1999/93/EC of the European Parliament and of the Council of 13 December 1999 on a Community framework for electronic signatures, $O J \mathrm{~L}$ 13, 19.1.2000, pp. 12-20.

EDPB (2019), Guidelines 4/2019 on Article 25 Data Protection by Design and by Default adopted on 13 November 2019. European Data Protection Board Plenary meeting, 12-13 November 2019.

EDPS (2012), Opinion of the European Data Protection Supervisor on the Commission proposal for a Regulation of the European Parliament and of the Council on trust and confidence in electronic transactions in the internal market (Electronic Trust Services Regulation), European Data Protection Supervisor. Retrieved from https://edps.europa.eu/sites/edp/files/publication/12-09-27_electronic_ trust_services_en_0.pdf [accessed 7 Nov 2020]

ENISA (2014), Privacy and Data Protection by Design-from policy to engineering, The European Union Agency for Cybersecurity. Retrieved from https://www. enisa.europa.eu/publications/privacy-and-data-protection-by-design [accessed 7 Nov 2020]

European Commission (n.d., a), 'eIDAS Cooperative Framework.' Retrieved from https://ec.europa.eu/cefdigital/wiki/display/EIDCOOPNET/eIDAS+ Cooperation+Network [accessed 7 Nov 2020]

European Commission (n.d., b), 'eIDAS-Implementing Acts.' Retrieved from https:// ec.europa.eu/futurium/en/content/eidas-implementing-acts [accessed 7 Nov 2020]

European Commission (n.d., c), 'eIDAS Level of Assurance.' Retrieved from https://ec.europa.eu/cefdigital/wiki/display/CEFDIGITAL/eIDAS+Levels+of+ Assurance [accessed 7 Nov 2020] 
Those Who Shall Be Identified: The Data Protection Aspects of the Legal Framework for Electronic Identification in the European Union

European Commission (n.d., d), 'EU Trusted Lists of Trust Service Providers.' Retrieved from https://ec.europa.eu/digital-single-market/en/eu-trusted-liststrust-service-providers [accessed 7 Nov 2020]

Fuster, G. (2014), The Emergence of Personal Data Protection as a Fundamental Right in the EU, Cham: Springer.

Hamulák, J. \& Nevická, D. (2020), 'The Slovak v the Danish labor law approach to COVID 19 pandemic,' International and Comparative Law Review, vol. 20, no. 2, pp. 231-238. https://doi.org/10.2478/iclr-2020-0026

Jasmontaite, L.; Kamara, I.; Zanfir-Fortuna, G. \& Leucci, S. (2018), 'Data protection by design and by default: Framing guiding principles into legal obligations in the GDPR,' European Data Protection Law Review, vol. 4(2018), no. 2, pp. 168-189. https://doi.org/10.21552/edpl/2018/2/7

Kesa, A. \& Kerikmäe, T. (2020), 'Artificial intelligence and the GDPR: Inevitable nemeses?' TalTech Journal of European Studies, vol. 10, no. 3(32), pp. 68-90. https://doi.org/10.1515/bjes-2020-0022

Porcedda, M. G. (2018), 'On boundaries-finding the essence of the right to the protection of personal data,' in R. Leenes, R. van Brakel, S. Gutwirth \& P. De Hert (eds.) Data Protection and Privacy: The Internet of Bodies, Oxford: Hart Publishing.

Project FIDIS (n.d.), [Homepage]. Retrieved from http://www.fidis.net/ [accessed 7 Nov 2020]

Project STORK (n.d.), [Homepage]. Retrieved from https://cordis.europa.eu/project/ $\mathrm{id} / 297263$ [accessed 7 Nov 2020]

Razmetaeva, Y. (2020), 'The right to be forgotten in the European perspective,' TalTech Journal of European Studies, vol. 10, no. 1(30), pp. 58-76.

https://doi.org/10.1515/bjes-2020-0004

Regulation (EU) 2016/679 of the European Parliament and of the Council of 27 April 2016 on the protection of natural persons with regard to the processing of personal data and on the free movement of such data, and repealing Directive 95/46/EC (General Data Protection Regulation), OJ L 119, 4.5.2016, pp. 1-88.

Regulation (EU) no. 910/2014 of the European Parliament and of the Council of 23 July 2014 on electronic identification and trust services for electronic transactions in the internal market and repealing Directive 1999/93/EC, OJ L 257, 28.8.2014, pp. 73-114.

Romano, F. B. (2013), The Right to the Protection of Personal Data: A New Fundamental Right of the European Union. Retrieved from https://papers.ssrn. com/sol3/papers.cfm?abstract_id=2330307 [accessed 7 Nov 2020]

Rubinstein, I. S. (2011), 'Regulating privacy by design,' Berkeley Technology Law Journal, vol. 26, no. 3, pp. 1409-1456. 
van der Sloot, B. (2015), 'Do privacy and data protection rules apply to legal persons, and should they? A proposal for a two-tiered system,' Computer Law \& Security Review, vol. 31, no. 1, pp. 26-45. https://doi.org/10.1016/j.clsr.2014.11.002

The Modinis IDM Study Team (2005), 'Modinis study on identity management in eGovernment: Common terminological framework for interoperable electronic identity management,' Consultation paper v2.01. Retrieved from http://ec.europa.eu/information_society/activities/ict_psp/documents/eid_ terminology_paper.pdf [accessed 7 Nov 2020]

Tsakalakis, N.; Stalla-Bourdillon, S. \& O'Hara, K. (2016), 'What's in a name: the conflicting views of pseudonymisation under eIDAS and the general data protection regulation,' in D. Hühnlein, H. Roßnagel, C. H. Schunck \& M. Talamo (eds.) Open Identity Summit 2016, Bonn: Gesellschaft für Informatik e.V., pp. 167-174.

Tsakalakis, N.; Stalla-Bourdillon, S. \& O'Hara, K. (2018), 'Data protection by design for cross-border electronic identification: Does the eIDAS interoperability framework need to be modernised?' in E. Kosta et al. (eds.) Privacy and Identity Management. Fairness, Accountability and Transparency in the Age of Big Data, 13th IFIP WG 9.2, 9.6/11.7, 11.6/SIG 9.2.2, International Summer School, Vienna, Austria, August 20-24, 2018, Revised Selected Papers, pp. 255-274.

Tzanou, M. (2013), 'Data protection as a fundamental right next to privacy? "Reconstructing" a not so new right,' International Data Privacy Law, vol. 3, no. 2, pp. 88-99. https://doi.org/10.1093/idpl/ipt004

Zaccaria, A.; Schmidt-Kessel, M.; Schulze, R. \& Gambino, A. M. (2020), EU eIDAS Regulation: Article-by-Article Commentary, Oxford: Bloomsbury Publishing PLC. 